\title{
Preliminary site classification of free-field strong motion stations based on Wenchuan earthquake records*
}

\author{
Ruizhi Wen ${ }^{1,2, \uparrow}$ Yefei Ren ${ }^{1}$ Zhenghua Zhou ${ }^{1}$ and Dacheng Shi ${ }^{1}$ \\ ${ }^{1}$ Institute of Engineering Mechanics, China Earthquake Administration, Harbin 150080, China \\ ${ }^{2}$ College of Architecture and Civil Engineering, Beijing University of Technology, Beijing 100022, China
}

\begin{abstract}
During the great Wenchuan earthquake, about 460 permanent free-field stations in National Strong Motion Observation Network System (NSMONS) of China captured the main shock acceleration records. These records can be applied to site effect analyses, and then the site classification of those permanent stations can be carried out firstly, which will served as the fundamental information for further research. In this paper, the site of near-fault stations is classified by horizontal-to-vertical spectral ratio (HVSR) method according to the site class description of Japan earthquake resistant design code and response spectral shapes (RSS) method following the site class description of the 1997 Uniform Building Code (UBC) provisions. Then based on the detailed borehole data of those free-field stations, the equivalent shear wave velocity and overburden thickness are calculated and the site classifications are given by Chinese code for seismic design of buildings. Furthermore, for the stations having successful microtremor test data, the site dominant periods are computed to verify the results of site classification. Finally, combined with all the above results, the recommended site classes of near-fault permanent free-field stations are given.
\end{abstract}

Key words: site classification; Wenchuan earthquake; strong motion station; acceleration record

CLC number: P315.9 Document code: A

\section{Introduction}

Many post-earthquake investigations and experiences have showed that local site condition has great effects on characteristics of ground motion and earthquake damage (Hu et al, 1980; Zhou, 1990; China Earthquake Investigation Group to Japan, 1995). The different site classifications can induce the amplifications of response spectra in different period ranges. If the natural period of a building is close to the predominant period of ground, it could cause the building resonance and lead to severe damage. The phenomenon has been recognized even early after 1906 California earthquake and the investigations have presented that the damage extent is significantly different when the similar buildings are located on the different classified site near the San Francisco bay area. The subsequent earthquakes,

\footnotetext{
* Received 3 September 2009; accepted in revised form 1 December 2009; published 10 February 2010

•Corresponding author. e-mail: ruizhi@iem.net.cn

(c) The Seismological Society of China and Springer-Verlag Berlin Heidelberg 2010
}

such as 1976 Tangshan earthquake and 1985 Mexico earthquake, also support this recognization that there is a strong relationship between site condition and earthquake damage.

With rapid development of strong motion observation technology, lots of acceleration records in different sites have been accumulated in USA, Japan and European. Based on these records, the effect of site condition on ground motion could be evaluated qualitatively, and also some empirical equations about ground motion parameters with different site conditions were given (Mohraz, 1976; Crouse and McGuire, 1996; Li and Peng, 2001; Dong et al, 2006).

The response spectral shape (RSS) method for site classification was prevalent in the early stage of few strong motion records. Seed et al (1976) succeeded in the site classification using the normalized shape characteristics of response spectra at a $5 \%$ damping ratio. In their research, 104 strong motion records were selected from 23 earthquakes to calculate the mean acceleration spectra curves of the four kinds of site classes, which are respectively rock, stiff soil, deep cohesionless soil, soft 
to medium clay and sand. However, the response spectra shapes significantly depend on magnitude, distance and focal depth (Yamazaki and Ansary, 1997), so RSS method is commonly used for verifying results of other site classification methods (Lee et al, 2001; Phung et al, 2006).

At present, the index method is generally adopted for site classification, but the index and the description of site class are slightly different in different countries. In China seismic codes, there are general two indexes, the equivalent velocity of shear wave and thickness of site soil layer. In addition, a method of site classification using strong motion records is explored, named horizontal-to-vertical spectral ratio (HVSR) method by analyzing the predominant periods of the soil. The spectral ratio method was proposed firstly by Nakamura (1989), also called Nakamura method. It is used for estimating site characteristic based on horizontal-to-vertical Fourier amplitude spectral ratio of the microtremor at the same measuring location. Yamazaki and Ansary (1997) extended Nakamura method to assess site characteristics by using strong motion acceleration records, which indicated that the horizontal-to-vertical velocity spectral ratios are independent of magnitude, distance and focal depth. Zhao et al (2006) discussed a promising empirical site classification scheme based on acceleration records from the K-net strong motion network in Japan and proposed the mean response spectral ratio $(H / V)$ curves of four site classes. In Iran and Chinese Taiwan, the HVSR method was also adopted to classify the sites of free-field strong motion stations (Zare et al, 1999; Lee et al, 2001).

Recently, a new method of site classification by using surface geology and geomorphologic data was developed. Some classification maps were suggested in some regions or countries, such as in San Francisco (Wills et al, 2000) and Chinese Taiwan (Lee et al, 2001). In China, Wen et al (2008) also gave the nationwide site classification map by applying the digital geology map with the scale of 1:4000000, 1:2500000, 1:500000 and 1:200 000. Due to limitation to the scale of the geology or geomorphologic map, this method cannot cover the sites of strong motion stations with high resolution.

For the 2008 great Wenchuan earthquake, National Strong Motion Observation Network System (NSMONS) of China captured abundant acceleration records, which provided a good chance for site classification of the free-field strong motion stations. In this paper, HVSR, RSS and index methods are deployed. These prelimi- nary results will be helpful to give reference for further researches.

\section{Strong motion data in Wenchuan main shock}

At 14:28 on May 12, 2008 (Beijing time), a great earthquake occurred in Wenchuan, Sichuan province, China, of which the epicenter is located at $\left(31.021^{\circ} \mathrm{N}\right.$, $\left.103.367^{\circ} \mathrm{E}\right)$, the surface wave magnitude is $M_{\mathrm{S}} 8.0$ and the focal depth is $14 \mathrm{~km}$. This shock was felt at most part of China except Heilongjiang province, Jilin province and Xinjiang autonomous region. National Strong Motion Observation Network System (NSMONS) of China have been built during the Tenth Five-year Plan and just started to run by China Earthquake Administration since March of 2008. Fortunately, 455 free-field stations in 19 provinces, municipalities and autonomous regions captured the main shock (China Earthquake Administration, 2008). Not only these acceleration records have greatly expanded the worldwide strong motion data, but also the records obtained from near-fault stations have filled a gap for the near-fault records from destructive earthquakes in China (Li et al, 2008). There are more than 560 time-history components with peak ground acceleration (PGA) larger than $10 \mathrm{~cm} \cdot \mathrm{s}^{-2}, 226$ larger than $50 \mathrm{~cm} \cdot \mathrm{s}^{-2}, 115$ larger than $100 \mathrm{~cm} \cdot \mathrm{s}^{-2}, 42$ larger than $200 \mathrm{~cm} \cdot \mathrm{s}^{-2}, 16$ larger than $400 \mathrm{~cm} \cdot \mathrm{s}^{-2}$, and 7 larger than $600 \mathrm{~cm} \cdot \mathrm{s}^{-2}$. The largest PGAs, which are $957.7 \mathrm{~cm} \cdot \mathrm{s}^{-2}, 652.9 \mathrm{~cm} \cdot \mathrm{s}^{-2}$ and $948.1 \mathrm{~cm} \cdot \mathrm{s}^{-2}$ in the $\mathrm{EW}$, NS, and UD directions, respectively, were recorded at Wolong station in Wenchuan county, Sichuan province.

In this paper, 77 free-field stations are selected for site classifications, which are all near the Longmenshan fault belt, as shown in Figure 1. For the far-fault stations, the strong motion records mainly contain middlefrequency and low-frequency components, but for the near-fault stations they mainly reserve high-frequency information well and can reflect the site characteristics really with the HVSR and RSS methods. For the near-fault stations, the peak periods of response spectra ratios of those records have relatively higher values which are easily identified. The high-frequency ground motion will attenuate quickly while it starts to propagate from the hypocenter. It was found that the peak periods of the far-field station were close to $1 \mathrm{~s}$ or even longer when the response spectrum was analyzed by using the HVSR or RSS method, and the site classification could lead to the false results, which mostly could be grouped 
as the soft sites.

By applying strong motion records obtained in the Wenchuan main shock, the corrected records are processed by baseline correction to subtract the mean values of the $1 \mathrm{~s}$ uncorrected pre-event acceleration records.

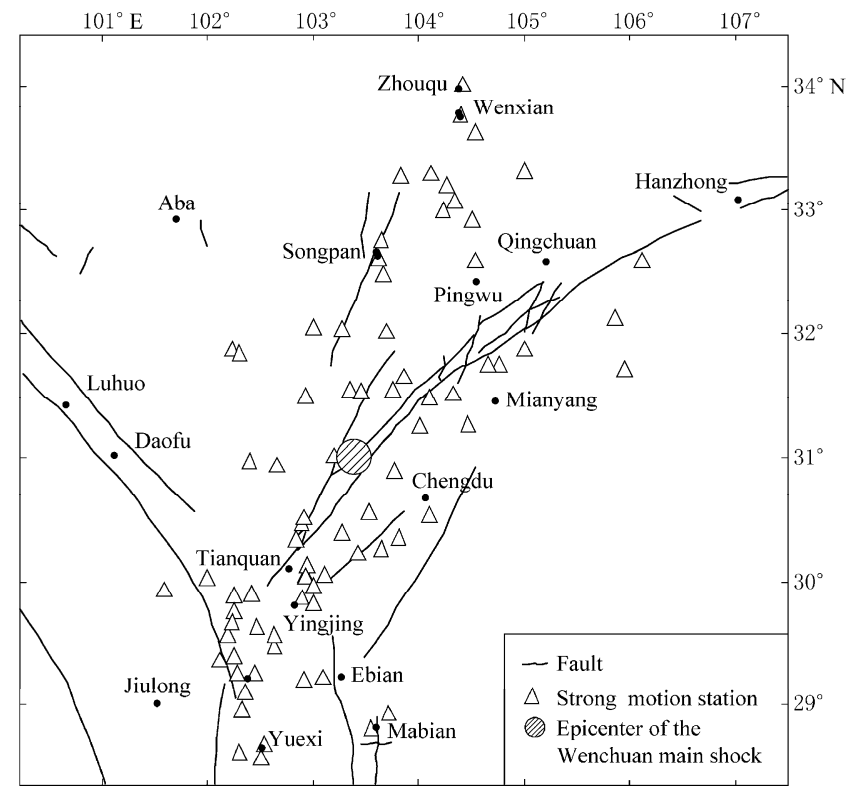

Figure 1 Free-field strong motion stations for site classification in this paper.

\section{Site classifications of the strong motion stations}

\subsection{HVSR classification}

The horizontal-to-vertical spectral ratio (HVSR) method was proposed firstly by Yamazaki and Ansary (1997). Zhao et al (2006) improved this approach and confirmed its usefulness from the records of the K-net strong motion network. The horizontal-to-vertical spectral ratios of the velocity response spectra of the acceleration records at a 5\% damping ratio, were calculated for the strong motion stations of which the site classes were already determined, and then the geometric mean spectral ratios of different site classes were given. When classifying site classes of Taiwan free-field strong motion stations, Lee et al (2001) concluded that this method is very helpful for evaluating class of a site where the geological and geotechnical information is lacking, and its classification results are reliable by comparing with the results of Kuo (1992, 1993, 1994). Fukushima et al (2007) discussed that although the HVSR method has a shortcoming for the site with a broadband response, in most cases it is useful for site classification even when information on the soil profile is lacking. Furthermore, the HVSR method is improved by designing a new index for probabilistic distribution of spectral shape (Ghasemi et al, 2009), or using neural network technique (self-organizing map, SOM) (Garniel et al, 2009), which makes the method more reasonable.

Zhao et al (2006) explained why the ratios of 5\% damped velocity response spectra were used instead of traditional Fourier spectral ratios for the site classification. The Fourier spectra have many spikes; for extracting the spectral peaks corresponding to the site characteristics, smoothing is evitable. In order to remove any such spikes causing unrelated site responses, more records are needed to average the spectral ratios of those records. Hence, more time is needed and the variability of the peak periods is great. As is well known, the undamped velocity spectrum of strong motion record is quite similar to the Fourier spectrum except at the very short periods; furthermore, adding 5\% damping ratio can make them have smoothing effect. For their no smoothing, high work efficiency and low variability, the $H / V$ ratios of $5 \%$ damped velocity response spectra can be used for classifying site categories appropriately.

Figure 2 illustrates the empirical HVSR for four site classes, and SC I, SC II, SC III, SC IV represent the rock and stiff soil, hard soil, medium soil, soft soil, respectively. The definitions of these four site classes can be explained in Table 1, which are approximately corresponding to NEHPR site classes $\mathrm{A}+\mathrm{B}, \mathrm{C}, \mathrm{D}$ and $\mathrm{E}$. It clearly shows the shapes of HVSR are distinguishably different for each site class, and the peak periods $\left(T_{\mathrm{R}}\right)$ of HVSR at $0.15 \mathrm{~s}, 0.25 \mathrm{~s}, 0.4 \mathrm{~s}$ and $0.8 \mathrm{~s}$ are reasonably similar to the site nature periods $\left(T_{\mathrm{n}}\right)$ for SC I, SC II, SC

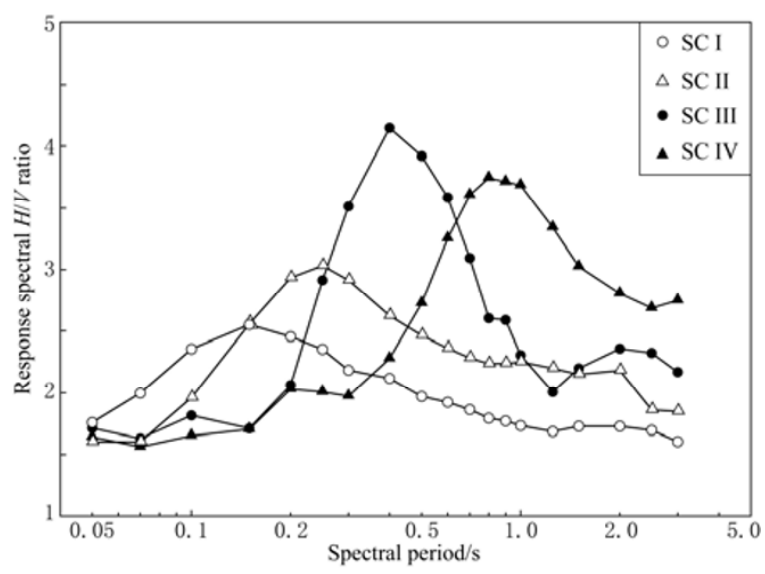

Figure 2 Mean response spectral $H / V$ ratios with different site classes (Zhao et al, 2006). 
III and SC IV. So we determined the site class according to the HVSR peak periods within the site natural period bands categorized in Table 1 . Then the mean response spectra of horizontal ground motion for each record by averaging the natural logarithms could be as follows:

$$
\ln H=\frac{\ln g_{\mathrm{EW}}+\ln g_{\mathrm{NS}}}{2},
$$

where $H$ is the average horizontal component, and $g_{\mathrm{NS}}$ and $g_{\mathrm{EW}}$ are the north-south and east-west components of ground motion, respectively.

Table 1 Site class definition used in Japan for engineering design practice and NEHRP site classes

\begin{tabular}{cccc}
\hline Site class ${ }^{1}$ & Site natural period $T_{\mathrm{n}} / \mathrm{s}$ & Average shear wave velocity $v_{30} / \mathrm{m}^{-\mathrm{s}^{-1}}$ & NEHPR class $^{2}$ \\
\hline SC I (Rock/stiff soil) & $T_{\mathrm{n}}<0.2$ & $v_{30}>600$ & $\mathrm{~A}+\mathrm{B}$ \\
SC II (Hard soil) & $0.2 \leq T_{\mathrm{n}}<0.4$ & $300<v_{30} \leq 600$ & $\mathrm{C}$ \\
SC III (Medium soil) & $0.4 \leq T_{\mathrm{n}}<0.6$ & $200<v_{30} \leq 300$ & $\mathrm{D}$ \\
SC IV (Soft soil) & $T_{\mathrm{n}} \geq 0.6$ & $v_{30} \leq 200$ & $\mathrm{E}$ \\
\hline
\end{tabular}

Note: 1 from Japan Road Association (1990), and 2 from Building Seismic Safety Council (2000).

Consequently, 77 strong motion sites were categorized into $27 \mathrm{SC}$ I sites, $30 \mathrm{SC}$ II sites, $16 \mathrm{SC}$ III sites and 4 SC IV sites, seen in appendix.

\subsection{RSS classification}

The response spectral shape (RSS) was used to represent a characteristic of soil response originally proposed by Borcherdt (1970). He estimated the soil response by using the ratios of spectra on soil sites to those on rock soil sites, with the assumption that the rock sites were no amplification. Seed et al (1976) suggested the mean 5\% damped acceleration response spectral shapes for the four site classes. However, only 104 records obtained from 23 earthquakes were collected due to lack of strong motion data at that time, and the estimation of site conditions was unreliable. Lee et al (2001) applied 1676 strong motion records captured from 11 destructive earthquakes, and the more reasonable mean response spectral shapes were suggested for site class $B$, site class $C$, site class $D$ and site class $E$ defined by NEHRP (Building Seismic Safety Council, 2000), as shown in Figure 3. And he confirmed that it is a very effective way to verify the classification results by other methods, which has been successfully used in site classification of Taiwan strong motion stations.

From Figure 3, the spectral shapes of class B and class $\mathrm{E}$ can be identified visibly because of the obvious peak period ranges, but those of class $C$ and class $D$ are not easily classified because their peak period ranges are rather close. So we combine class $\mathrm{C}$ and class $\mathrm{D}$ as class $\mathrm{C}+\mathrm{D}$ in this paper. The peak period $\left(T_{\mathrm{p}}\right)$ is referred as the primary classification criteria, and then the tangent of the falling segment of spectral shape is adopted as the secondary criteria if $T_{\mathrm{p}}$ can not be determined easily. Table 2 shows the detailed variation ranges of the mean acceleration response spectral shapes for each site classes. $S_{1}$ is the spectral amplitude when the period $(T)$

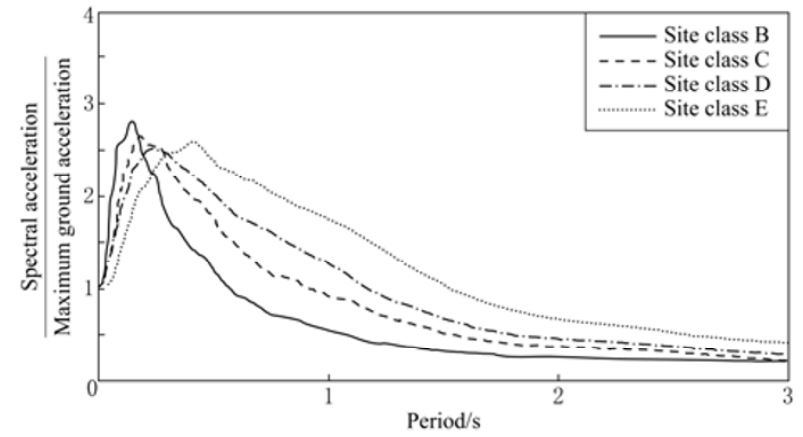

Figure 3 Mean acceleration response spectral shapes with different site classes (Lee et al, 2001).

Table 2 Mean acceleration response spectral shapes for NEHRP site classes

\begin{tabular}{ccc}
\hline Site class & Peak period $T_{\mathrm{p}} / \mathrm{s}$ & Spectral amplitude $S_{1}$ when $T=1 \mathrm{~s}$ \\
\hline B & $T_{\mathrm{p}}<0.17$ & $S_{1}<0.5$ \\
C $+\mathrm{D}$ & $0.17 \leq T_{\mathrm{p}}<0.42$ & $0.5 \leq S_{1}<1.5$ \\
E & $T_{\mathrm{p} \geq 0.42}$ & $S_{\mathrm{l}} \geq 1.5$ \\
\hline
\end{tabular}

is equal to $1 \mathrm{~s}$, and used as the index for judging the variation. For instance, if $T_{\mathrm{p}}$ of the acceleration records for one station is equal to around $0.17 \mathrm{~s}$ (maybe $0.16 \mathrm{~s}$ or $0.18 \mathrm{~s}$ ), then $S_{1}$ value is needed to further determine the class rather than just categorizing the site into class B simply. If $S_{1}$ is less than 0.5 , the site is classified as class B; otherwise, the site is classified as class $\mathrm{C}+\mathrm{D}$.

Consequently, 77 strong motion sites were grouped into 26 class B sites, 43 class $\mathrm{C}+\mathrm{D}$ sites and 8 class $\mathrm{E}$ sites by the above method.

\subsection{Index classification method}

The index method for site classification has been prevalent all over the world and introduced in the seismic design code by many countries. The indexes could be soil property, overburden thickness, shear wave velocity, SPT-N values, and so on. In Chinese provision (Ministry of Construction of the People's Republic of 
China and General Administration of Quality Supervision, Inspection and Quarantine of the People's Republic of China, 2001), four kinds of site classes, I, II, III and IV are given according to the equivalent shear wave velocity and overburden thickness. In this paper, for 77 stations, 58 groups of reliable borehole data were collected, and the values of aforementioned two indexes were calculated following Chinese code, and the site class results can be seen in appendix. Only two stations are class I, the others are class II. These stations are all located at high-altitude mountain areas in Sichuan province, where Quaternary soil layer is rather thin, even in some area the bedrock is exposed. Thus the site class either I or II looks reasonable and the results can also verify the classifications by HVSR method and RSS method.

\subsection{Predominant periodsf free-field station}

Although the Nakamura method depends on some assumptions and there is no an acceptable explanation to this method yet, it can get more accuracy predominant periods than those of other microtremor analysis methods. As a result, the Nakamura method has been used widely in engineering field (Konno and Ohmachi, 1998; Guo, 2000; Zhai et al, 2004). When the free-field station are to be built, the microtremor test is required for analyzing the background characteristics near the station and 59 groups of microtremor data for 77 stations had been collected. Having reviewed these microtremor records and abandoned the segments with the disturbances and zero-line offset, we select the Nakamura method in this paper to calculate site predominant periods.

In this paper, a segment of microtremor records with less disturbances and straight waveform have been carefully selected for each station, and the time length of 2048 sampling points are retained. The mean voltage value of the first $1 \mathrm{~s}$ for the strong motion instruments was calculated and subtracted from the uncorrected record to obtain the corrected record. Then the microtremor record was band-passed filtered between 0.1 $\mathrm{Hz}$ and $10 \mathrm{~Hz}$. Later, the horizontal and vertical Fourier spectra were smoothed by Hanning window. It should be explained that the horizontal Fourier spectrum were calculated by calculating a complex horizontal microtremor component $h(\mathrm{t})$ from

$$
h(t)=h_{\mathrm{EW}}(t)+\mathrm{i} h_{\mathrm{NS}}(t)
$$

where $h_{\mathrm{EW}}(t)$ and $h_{\mathrm{NS}}(t)$ are the east-west and north-south components of microtremor, respectively. The peak period of the horizontal-to-vertical Fourier spectral ratios $(H / V)$ was determined as the predominant period of the station site and the results of all 59 stations can be seen in appendix.

\subsection{Classification results and discussion}

Rodriguez and Midorikawa (2002) presented that there was about $80 \%$ coincidence between the predominant period $\left(T_{\mathrm{m}}\right)$ of the microtremor and the peak HVSR period $\left(T_{\mathrm{R}}\right)$ of ground motion records at strong motion stations when the period was shorter than $0.5 \mathrm{~s}$. In this paper, to discuss the relationship between $T_{\mathrm{m}}$ and $T_{\mathrm{R}}$, we adopted the linear equation

$$
T_{\mathrm{R}}=\alpha T_{\mathrm{m}}+\beta
$$

where $\alpha$ and $\beta$ are statistical constants determined by regression analysis. The results show $\alpha$ equals to 1.008 with standard error of 0.153 , and $\beta$ equals to 0.073 with standard error of 0.040 . So the relationship between $T_{\mathrm{m}}$ and $T_{\mathrm{R}}$ was given by

$$
T_{\mathrm{R}}=1.008 T_{\mathrm{m}}+0.073 \text {. }
$$

Figure 4 illustrates this relationship (solid line) obtained by linear fitting. The solid line is above the dashed line which represents $T_{\mathrm{m}}$ equals to $T_{\mathrm{R}}$. It can draw a conclusion that the values of $T_{\mathrm{m}}$ and $T_{\mathrm{R}}$ computed in this paper are approximately consistent with each other, but a little greater. This is substantially the same as the conclusion given by Rodriguez and Midorikawa (2002). Therefore, HVSR peak periods calculated in this paper are relatively accurate, and the site classifications by HVSR method are also acceptable.

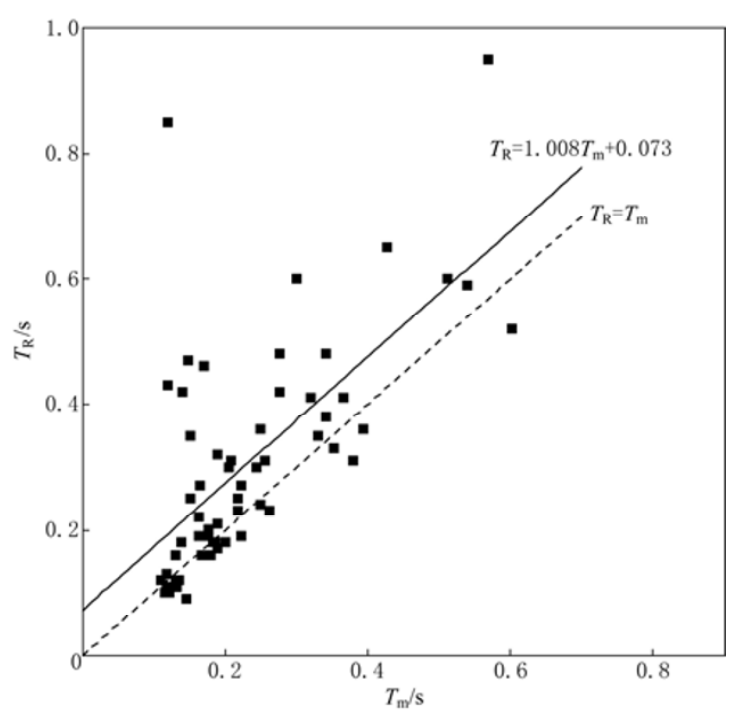

Figure 4 Linear relationship between site predominant period $\left(T_{\mathrm{m}}\right)$ and HVSR peak period $\left(T_{\mathrm{R}}\right)$. 
Comparison between the HVSR classification results and that of RSS classification in Table 3 shows that most of SC I sites of the stations match well with those of the site class B, so do the SC II and SC III sites with the site class $\mathrm{C}+\mathrm{D}$. We cannot draw the conclusion that
SC IV sites are well correlated with the site class E due to only four samples. It also illustrates that the HVSR and RSS classification results are reasonable and acceptable with the site definition in Japan and USA given in Table 1.

Table 3 Site class comparison among various methods

\begin{tabular}{|c|c|c|c|c|c|c|c|c|c|c|}
\hline \multirow{2}{*}{ HVSR } & \multicolumn{3}{|c|}{ RSS } & \multirow{2}{*}{ Total } & \multirow{2}{*}{$\mathrm{RSC}$} & \multicolumn{4}{|c|}{ HVRS } & \multirow{2}{*}{ Total } \\
\hline & B & $\mathrm{C}+\mathrm{D}$ & $\mathrm{E}$ & & & SC I & SC II & SC III & SC IV & \\
\hline SC I & 19 & 7 & 1 & 27 & $\mathrm{SC} \mathrm{I}$ & 26 & 0 & 3 & 1 & 30 \\
\hline SC II & 3 & 27 & 0 & 30 & SC II & 1 & 30 & 0 & 0 & 31 \\
\hline SC III & 4 & 8 & 4 & 16 & SC III & 0 & 0 & 12 & 1 & 13 \\
\hline SC IV & 0 & 1 & 3 & 4 & SC IV & 0 & 0 & 1 & 2 & 3 \\
\hline Total & 26 & 43 & 8 & 77 & Total & 27 & 30 & 16 & 4 & 77 \\
\hline \multirow{2}{*}{ RSC } & \multicolumn{3}{|c|}{ RSS } & \multirow{2}{*}{ Total } & \multirow{2}{*}{$\mathrm{RSC}$} & \multicolumn{4}{|c|}{$T_{\mathrm{m}} / \mathrm{s}$} & \multirow{2}{*}{ Total } \\
\hline & B & $\mathrm{C}+\mathrm{D}$ & E & & & $0.1-0.2$ & $0.2-0.4$ & $0.4-0.6$ & $>0.6$ & \\
\hline SC I & 22 & 6 & 2 & 30 & SC I & 24 & 1 & 0 & 0 & 25 \\
\hline SC II & 3 & 28 & 0 & 31 & SC II & 6 & 16 & 0 & 0 & 22 \\
\hline SC III & 1 & 9 & 3 & 13 & SC III & 1 & 6 & 3 & 0 & 10 \\
\hline SC IV & 0 & 0 & 3 & 3 & SC IV & 0 & 0 & 1 & 1 & 2 \\
\hline Total & 26 & 43 & 8 & 77 & Total & 31 & 23 & 4 & 1 & 59 \\
\hline
\end{tabular}

Note: HVSR stands for classification by horizontal-to-vertical spectral ratio, RSS for classification by response spectral shape, RSC for recommended site classes, and $T_{\mathrm{m}}$ for the site predominant period.
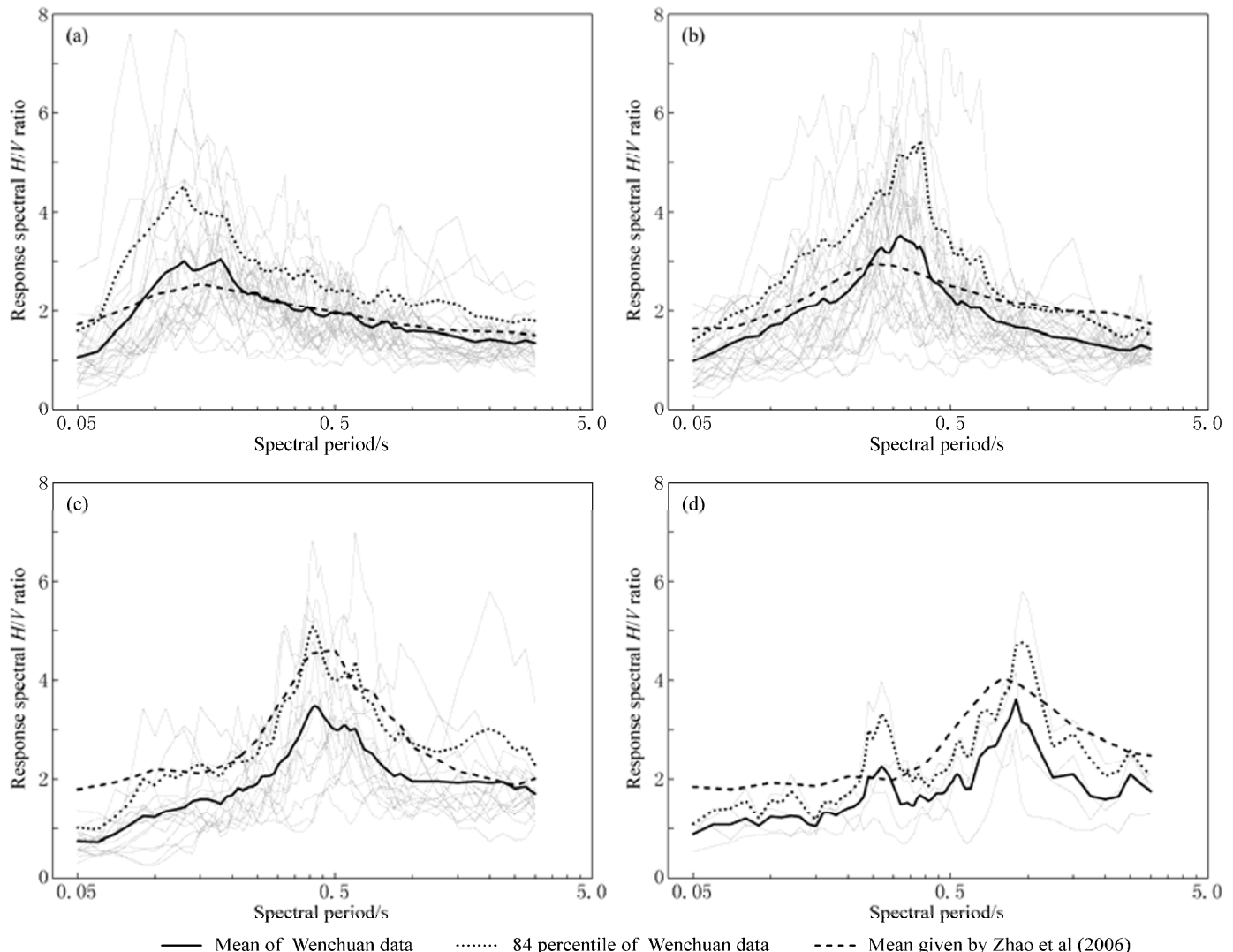

Figure 5 Comparisons between the HVSR results of Wenchuan strong motion data in this study and the mean HVSR given by Zhao et al (2006) for site classes I (a), II (b), III (c) and IV (d) with 5\% damping ratio.

In addition, the RSS and HVSR results were plotted in Figures 5 and 6. From Figure 5, it can be easily found the mean spectral ratio shapes for each site class are fairly consistent with those four site types given by 
Zhao et al (2006), especially for the peak period of each class. Comparison between Figure 6 with Figure 3 shows that the consistency also exists between the mean RSS of Wenchuan data and those by Lee et al (2001), implying that our classification results are acceptable except SC IV, which cannot be deduced by the consistency due to less samples.

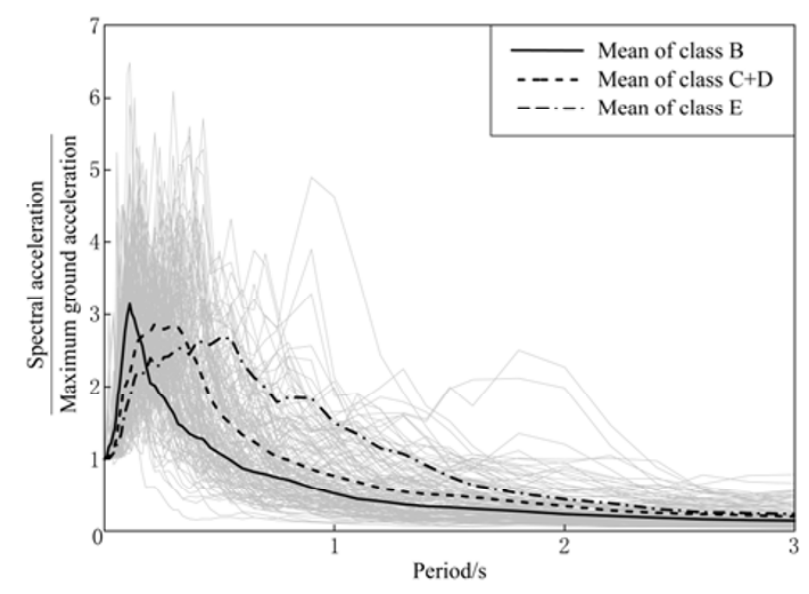

Figure 6 RSS results of the Wenchuan strong motion data and their mean acceleration response spectra with $5 \%$ damping ratio for each site class.

Considering the results given by the above three classification methods and the site microtremor predominant periods, the recommended site classes (RSC) of 77 strong motion stations were suggested to further researches on ground motion characteristics of the Wenchuan earthquake. Figure 7 demonstrates the classification distribution of those free-field stations, and Table 3 demonstrates the excellent coincidence among the RSC and the results of HVSR and RSS classifications. In this paper, compared the RSC with the site predominant periods, as shown in Table $3, T_{\mathrm{m}}$ is divided into four period ranges, $0.1-0.2 \mathrm{~s}, 0.2-0.4 \mathrm{~s}, 0.4-0.6 \mathrm{~s}$, and $>0.6 \mathrm{~s}$, which correspond with the $T_{\mathrm{n}}$ ranges given by Table 1 . The comparison results in Table 3 illustrate that the predominant periods of SC I sites are almost within $0.1-0.2$ $\mathrm{s}$, those of SC II sites are in 0.2-0.4 s, some ones are in $0.1-0.2 \mathrm{~s}$, and those of SC III and SC IV are uncertain because of less samples.

\section{Conclusions}

In this paper, the site classification of 77 NSMONS free-field strong motion stations were given mainly based on strong motion records from Wenchuan earthquake, borehole data and microtremor records of those

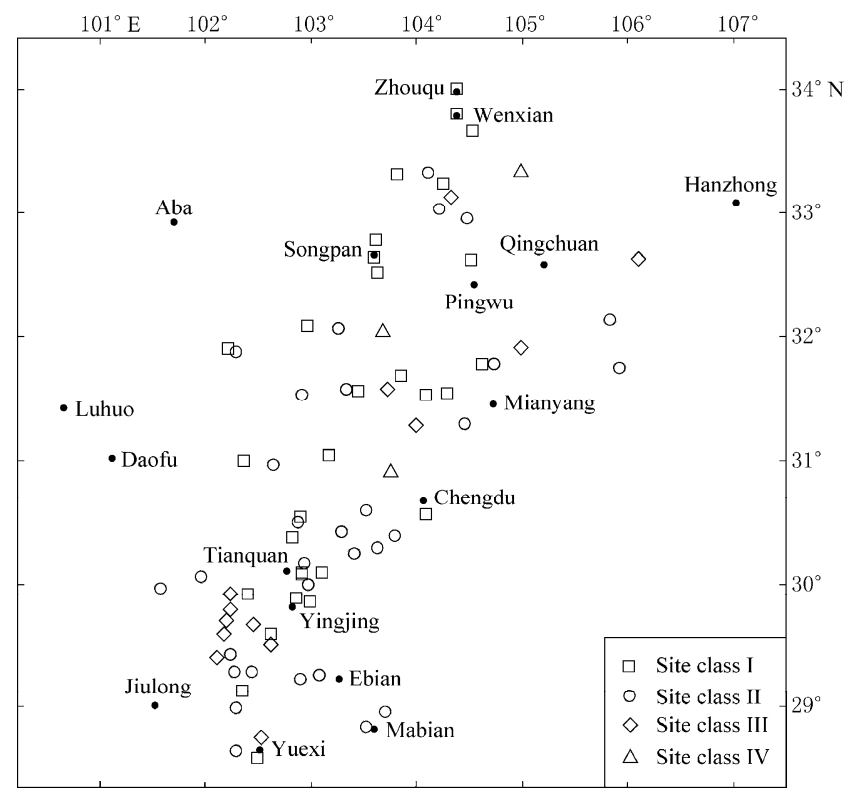

Figure 7 Suggested site classification map of near-fault stations based on the Wenchuan main shock records.

stations. The two kinds of methods for classifying the sites of near-fault stations, HVSR and RSS methods, were adopted, and the results from the two methods show high consistency. Meantime, index method was used for 58 stations with reliable borehole data. Nakamura method was used for calculating the site predominant periods for 59 of 77 stations, and the linear relationship between $T_{\mathrm{R}}$ and $T_{\mathrm{m}}$ was given by statistical regression analysis, which shows that $T_{\mathrm{R}}$ is a litter greater than $T_{\mathrm{m}}$, but they have quite the same trend.

Considering all kinds of classification results, we suggested the site classes of 77 strong motion stations are divided into four site classes: SC I (rock and stiff soil), SC II (hard soil), SC III (medium soil) and SC IV (soft soil), and the class results could be applied to further research. It should be paid attention that the site classes of 77 strong motion stations were recommended only based on Wenchuan main shock records. It does not mean this is the ultimate classification. After Wenchuan earthquake, more than ten thousands of aftershocks occurred, and the aftershock data should be introduced for verifying the site classes of near-fault free-field strong motion stations.

The site classification should also include some site investigations and the local site condition may affect the classification. For instance, when the station locates on a very steep mountain summit, the earthquake response spectra will be amplified at long periods, and its site will be classified into class SC IV or class E by HVSR or 
RSS method, even though the accelerometer is installed on the bedrock.

Acknowledgements The study is jointly supported by the projects from the Ministry of Science and Technology of China (No. 2009BK55B00), China Earthquake Administration (CEA) (No. 200808026) and Institute of Engineering Mechanics of CEA (No. 0618001). Thanks are given to China National Strong Motion Network Center for sharing the Wenchuan great earthquake strong motion data and related information.

\section{References}

Borcherdt R D (1970). Effects of local geology on ground motion near San Francisco Bay. Bull Seism Soc Amer 60(1): 29-61.

Building Seismic Safety Council (2000). The 2000 NEHRP Recommended Provisions for New Buildings and Other Structures. Part I (Provisions) and Part II (Commentary). FEMA 368/369, Washington D.C., 47.

China Earthquake Administration (2008). Report on Strong Earthquake Motion Records in China, Uncorrected Acceleration Records from Wenchuan $M_{\mathrm{S}} 8.0$ Earthquake. Seismological Press, Beijing, 1 (in Chinese).

China Earthquake Investigation Group to Japan (1995). Investigation of Great Hanshin Earthquake in Japan. Seismological Press, Beijing, 45 (in Chinese).

Crouse C B and McGuire J W (1996). Site response studies for purpose of revising NEHRP seismic provisions. Earthquake Spectra 12(3): 407-439.

Dong D, Zhou X Y, Xu G D and Ji J B (2006). Some analyses on effects of site classification on ground motion characteristics in Chi-Chi, Taiwan earthquake. Seismology and Geology 28(1): 22-36 (in Chinese with English abstract).

Fukushima Y, Bonilla L F, Scotti O and Douglas J (2007). Site classification using horizontal-to-vertical response spectral ratios and its impact when deriving empirical ground-motion prediction equations. $J$ Earthq Eng 11(5): 712-724.

Garniel R, Barbui L and Malisan P (2009). Improvement of HVSR technique by self-organizing map (SOM) analysis. Soil Dynam Earthq Eng 29(6): 1097-1 101.

Ghasemi H, Zare M, Fukushima Y and Sinaeian F (2009). Applying empirical methods in site classification, using response spectral ratio $(\mathrm{H} / \mathrm{V})$ : A case study on Iranian strong motion network (ISMN). Soil Dynam Earthq Eng 29(1): 121-132.

Guo M Z (2000). Analysis of Microtremor Wave Field and Its Application to Site Dynamic Characteristic Measurements. PhD Dissertation, Institute of Engineering Mechanics, China Earthquake Administration, Harbin, 1-133 (in Chinese with English abstract).

Hu Y X, Sun P S, Zhang Z Y and Tian Q W (1980). Effects of site condition on earthquake damage and ground motion. Earthq Eng Eng Vib 1(1): 34-41 (in Chinese with English abstract).

Japan Road Association (1990). Specifications for Highway Bridges. Part V: Seismic Design. Maruzen Co. Ltd., Tokyo, 207.

Konno K and Ohmachi T (1998). Ground-motion characteristics estimated from spectral ratio between horizontal and vertical components of microtremor. Bull Seism Soc Amer 88(1): 228-241.
Kuo K W (1992). The Geological Character of the CWB Strong Motion Network: Taipei area. Central Weather Bureau Report CW81-1A-10, 77 (in Chinese).

Kuo K W (1993). The Geological Character of the CWB Strong Motion NetWork: Taoyuan Hsinchu and Miaoli Area. Central Weather Bureau Report CW82-1A-11, 76 (in Chinese).

Kuo K W (1994). The Geological Character of the CWB Strong Motion NetWork: Chianan Area. Central Weather Bureau Report CW83-1A-12, 98 (in Chinese).

Lee C T, Cheng C T, Liao C W and Tsai Y B (2001). Site classification of Taiwan free-field strong-motion stations. Bull Seism Soc Amer 91(5): $1283-1297$.

Li X J and Peng Q (2001). Calculation and analysis of earthquake ground motion parameters for different site categories. J Earthq Eng Eng Vib 21(1): 29-36 (in Chinese with English abstract).

Li X J, Zhou Z H, Yu H Y, Wen R Z, Lu D W, Huang M, Zhou Y N and Cu J $\mathrm{W}$ (2008). Strong motion observations and recordings from the great Wenchuan earthquake. Earthq Eng Eng Vib 7(3): 235-246.

Ministry of Construction of the People's Republic of China and General Administration of Quality Supervision, Inspection and Quarantine of the People's Republic of China (2001). National Standard of People's Republic of China, Code for Seismic Design of Buildings. China Architecture \& Building Press, Beijing, 21-23 (in Chinese).

Mohraz B (1976). A study of earthquake response spectra for different geological conditions. Bull Seism Soc Amer 66(3): 915-935.

Nakamura Y (1989). A method for dynamic characteristics estimation of subsurface using microtremor on the ground surface. Quarterly Report of the Railway Technical Research Institute 30(1): 25-33.

Phung V, Atkinson G M and Lau D T (2006). Methodology for site classification estimation using strong ground motion data from the Chi-Chi, Taiwan, earthquake. Earthq Spectra 22(2): 511-531.

Rodriguez V H S and Midorikawa S (2002). Applicability of the H/V spectral ratio of microtremors in assessing site effects on seismic motion. Earthq Eng Struct Dynam 31(2): 261-279.

Seed H B, Ugas C and Lysmer J (1976). Site-dependent spectra for earthquakeresistant design. Bull Seism Soc Amer 66(1): 221-243.

Wen R Z, Shi D C and Ren Y F (2008). Site classification based on geological genesis and its application. Proceedings of the 14th World Conference on Earthquake Engineering. Beijing, China, Paper ID 04-02-0125.

Wills C J, Petersen M, Bryant W A, Reichle M, Saucedo G J, Tan S, Taylor G and Treiman J (2000). A site-conditions map for California based on geology and shear-wave velocity. Bull Seism Soc Amer 90(6B): S187-S208.

Yamazaki F and Ansary M A (1997). Horizontal-to-vertical spectrum ratio of earthquake ground motion for site characterization. Earthq Eng Struct Dynam 26(7): 671-689.

Zare M, Bard P Y and Ghafory-Ashtiany M (1999). Site characterizations for the Iranian strong motion network. Soil Dynam Earthq Eng 18(2): 101-123.

Zhai Y M, Li W Y and Jiang T (2004). Micro-tremor observation and its application to the evaluation of site predominant period. J Seis Res 27(3): 277-282 (in Chinese with English Abstract).

Zhao J X, Irikura K and Zhang J (2006). An empirical site-classification method for strong-motion stations in Japan using $\mathrm{H} / \mathrm{V}$ response ratio. Bull Seism Soc Amer 96(3): 914-925.

Zhou X Y (1990). Site Foundation Design Earthquake. Seismological Press, Beijing, 10-19 (in Chinese). 


\section{Appendix}

Table A The site classification list

\begin{tabular}{|c|c|c|c|c|c|c|c|c|c|}
\hline \multirow{2}{*}{ Station code } & \multirow{2}{*}{ Station name } & \multicolumn{2}{|c|}{ HVSR classification } & \multirow{2}{*}{$\begin{array}{c}\text { Site class } \\
\text { of RSS } \\
\text { classification }\end{array}$} & \multicolumn{3}{|c|}{ Index classification } & \multirow{2}{*}{$\begin{array}{l}T_{\mathrm{m}} \\
/ \mathrm{s}\end{array}$} & \multirow{2}{*}{$\mathrm{RSC}$} \\
\hline & & $\begin{array}{l}T_{\mathrm{R}} \\
/ \mathrm{s} \\
\end{array}$ & Site class & & $\begin{array}{l}H \\
/ \mathrm{m} \\
\end{array}$ & $\begin{array}{c}v_{20} \\
/\left(\mathrm{m} \cdot \mathrm{s}^{-1}\right)\end{array}$ & $\begin{array}{c}\text { Site } \\
\text { class }\end{array}$ & & \\
\hline 051AXT & Tashui, Anxian & 0.19 & SC I & $\mathrm{C}+\mathrm{D}$ & 9.9 & 191 & II & 0.163 & SC I \\
\hline 051BXD & Earthquake Office of Baoxing & 0.19 & SC I & B & & & & 0.177 & SC I \\
\hline 051BXY & Yanjing, Baoxing & 0.17 & SC I & $\mathrm{B}$ & 19.3 & 252 & II & 0.19 & $\mathrm{SC} \mathrm{I}$ \\
\hline 051BXZ & Minzhi, Baoxing & 0.36 & SC II & $\mathrm{C}+\mathrm{D}$ & 7.1 & 220 & II & 0.25 & SC II \\
\hline $051 \mathrm{CDZ}$ & Zhonghe, Chengdu & 0.11 & SC I & B & & & & 0.126 & SC I \\
\hline 051CXQ & Meteorological Bureau of Cangxi & 0.27 & SC II & $\mathrm{C}+\mathrm{D}$ & 4.9 & 321 & $\mathrm{I}$ & & SC II \\
\hline 051DXY & Yinping, Dayi & 0.33 & SC II & $\mathrm{C}+\mathrm{D}$ & $>20$ & 310 & II & 0.353 & SC II \\
\hline 051DYB & Baima, Deyang & 0.21 & SC II & $\mathrm{C}+\mathrm{D}$ & & & & 0.19 & SC II \\
\hline 051GYS & Shijing, Guangyuan & 0.23 & SC II & $\mathrm{C}+\mathrm{D}$ & 9.4 & 202 & II & 0.218 & SC II \\
\hline $051 \mathrm{GYZ}$ & Zengjia, Guangyuan & 0.46 & SC III & $\mathrm{C}+\mathrm{D}$ & 11.3 & 188 & II & 0.171 & SC III \\
\hline 051HSD & Earthquake Office of Heishui & 0.09 & SC I & B & $>20$ & 294 & II & 0.146 & SC I \\
\hline 051HSL & Shuangliusuo, Heishui & 0.38 & SC II & $\mathrm{C}+\mathrm{D}$ & $>20$ & 290 & II & & SC II \\
\hline 051HYJ & Jiuxiang, Hanyuan & 0.48 & SC III & E & 11.7 & 372 & II & 0.277 & SC III \\
\hline 051HYQ & Qingxi, Hanyuan & 0.12 & SC I & B & $>20$ & 291 & II & 0.135 & SC I \\
\hline 051HYW & Wusihe, Hanyuan & 0.35 & SC II & $\mathrm{C}+\mathrm{D}$ & 14 & 295 & II & 0.151 & SC II \\
\hline 051HYY & Yidong, Hanyuan & 0.42 & SC III & $\mathrm{C}+\mathrm{D}$ & 7.6 & 387 & II & & SC III \\
\hline 051JKH & Jinkouhe, Leshan & 0.38 & SC II & $\mathrm{C}+\mathrm{D}$ & $>20$ & 302 & II & & SC II \\
\hline 051JYC & Chonghua, Jiangyou & 0.41 & SC III & $\mathrm{C}+\mathrm{D}$ & 5.7 & 158 & II & 0.366 & SC III \\
\hline 051JYD & Earthquake Station of Jiangyou & 0.27 & SC II & $\mathrm{C}+\mathrm{D}$ & 8.4 & 336 & II & 0.223 & SC II \\
\hline 051JYH & Hanzeng, Jiangyou & 0.16 & SC I & B & 17.5 & 237 & II & 0.18 & SC I \\
\hline 051JZB & Baihe, Jiuzhai & 0.19 & SC I & $\mathrm{C}+\mathrm{D}$ & $>20$ & 283 & II & 0.223 & SC II \\
\hline 051JZG & Guoyuan, Jiuzhai & 0.60 & SC III & $\mathrm{C}+\mathrm{D}$ & $>20$ & 263 & II & 0.512 & SC III \\
\hline 051JZW & Wujiao, Jiuzhai & 0.31 & SC II & $\mathrm{C}+\mathrm{D}$ & 16.2 & 391 & II & 0.256 & SC II \\
\hline $051 \mathrm{JZY}$ & Yongfeng, Jiuzhai & 0.18 & SC I & B & $>20$ & 273 & II & 0.201 & SC I \\
\hline $051 \mathrm{JZZ}$ & Zhangzha, Jiuzhai & 0.10 & SC I & B & & & & 0.122 & SC I \\
\hline $051 \mathrm{KDG}$ & Xiaba, Kangding & 0.31 & SC II & $\mathrm{C}+\mathrm{D}$ & $>20$ & 251 & II & 0.209 & SC II \\
\hline $051 \mathrm{KDT}$ & Kangding & 0.36 & SC II & $\mathrm{C}+\mathrm{D}$ & & & & 0.394 & SC II \\
\hline 051LDD & Detuo, Luding & 0.60 & SC III & E & $>20$ & 314 & II & 0.301 & SC III \\
\hline 051LDJ & Jiajun, Luding & 0.48 & SC III & B & $>20$ & 265 & II & 0.341 & SC III \\
\hline 051LDL & Lengqi, Luding & 0.41 & SC III & $\mathrm{C}+\mathrm{D}$ & $>20$ & 288 & II & 0.32 & SC III \\
\hline 051LDS & Water supply Factory of Luding & 0.51 & SC III & $\mathrm{C}+\mathrm{D}$ & $>20$ & 343 & II & & SC III \\
\hline 051LSF & Feixianguan, Lushan & 0.16 & SC I & B & 6.9 & 242 & II & 0.131 & SC I \\
\hline 051LSH & Fenghe, Lushan & 0.18 & $\mathrm{SC} \mathrm{I}$ & $\mathrm{C}+\mathrm{D}$ & 6.9 & 324 & II & 0.183 & $\mathrm{SC} \mathrm{I}$ \\
\hline 051LSJ & Parenthood Office of Lushan & 0.23 & SC II & $\mathrm{C}+\mathrm{D}$ & 2.3 & 162 & $\mathrm{I}$ & 0.263 & SC II \\
\hline 051LXM & Muka, Lixian & 0.40 & SC II & $\mathrm{C}+\mathrm{D}$ & $>20$ & 261 & II & & SC II \\
\hline 051LXS & Shaba, Lixian & 0.30 & SC II & B & & & & 0.205 & SC II \\
\hline 051LXT & Taoping, Lixian & 0.47 & SC III & B & $>20$ & 281 & II & 0.148 & $\mathrm{SC} \mathrm{I}$ \\
\hline 051MBD & Earthquake Office of Mabian & 0.33 & SC II & $\mathrm{C}+\mathrm{D}$ & & & & & SC II \\
\hline $051 \mathrm{MCL}$ & Lidian, Muchuan & 0.38 & SC II & $\mathrm{C}+\mathrm{D}$ & 11.5 & 227 & II & & SC II \\
\hline 051MED & Earthquake Office of Barkam & 0.11 & $\mathrm{SC} \mathrm{I}$ & B & 5.6 & 243 & II & 0.133 & SC I \\
\hline 051MEZ & Zhuokeji, Barkam & 0.22 & SC II & $\mathrm{C}+\mathrm{D}$ & 18.1 & 284 & II & 0.163 & SC II \\
\hline $051 \mathrm{MNC}$ & Caogu, Mianning & 0.32 & SC II & $\mathrm{C}+\mathrm{D}$ & $>20$ & 409 & II & 0.19 & SC II \\
\hline 051MXD & Diexi, Maoxian & 0.95 & SC IV & E & $>20$ & 238 & II & 0.569 & SC IV \\
\hline $051 \mathrm{MXN}$ & Nanxin, Maoxian & 0.59 & SC III & E & $>20$ & 348 & II & 0.539 & SC III \\
\hline 051MXT & Earthquake Office of Maoxian & 0.18 & SC I & $\mathrm{C}+\mathrm{D}$ & & & & 0.186 & SC I \\
\hline 051MZQ & Qingping, Mianzhu & 0.18 & SC I & B & 9.1 & 339 & II & 0.138 & SC I \\
\hline 051PJD & Daxing, Pujiang & 0.38 & SC II & $\mathrm{C}+\mathrm{D}$ & $>20$ & 318 & II & 0.341 & SC II \\
\hline 051PJW & Wuxing, Pujiang & 0.30 & SC II & $\mathrm{C}+\mathrm{D}$ & $>20$ & 290 & II & 0.244 & SC II \\
\hline 051PWM & Muzuo, Pingwu & 0.42 & SC III & B & 19 & 392 & II & 0.141 & SC I \\
\hline 051PXZ & Zoushishan, Pixian & 0.52 & SC III & $\mathrm{E}$ & & & & 0.602 & SC IV \\
\hline 051QLY & Youzha, Qionglai & 0.25 & SC II & B & 6.2 & 216 & II & 0.218 & SC II \\
\hline 051SFB & Bajiao, Shifang & 0.42 & SC III & $\mathrm{C}+\mathrm{D}$ & 12 & 185 & II & 0.277 & SC III \\
\hline 051SMC & Caluo, Shimian & 0.11 & SC I & B & $>20$ & 298 & II & 0.118 & SC I \\
\hline 051SMK & Caoke, Shimian & 0.65 & SC IV & $\mathrm{C}+\mathrm{D}$ & $>20$ & 270 & II & 0.427 & SC III \\
\hline 051SML & Liziping, Shimian & 0.25 & $\mathrm{SC}$ II & $\mathrm{C}+\mathrm{D}$ & $>20$ & 310 & II & 0.151 & SC II \\
\hline 051SMM & Meiluo, Shimian & 0.31 & SC II & $\mathrm{C}+\mathrm{D}$ & & & & 0.379 & SC II \\
\hline 051SMW & Wajiao, Shimian & 0.27 & SC II & $\mathrm{C}+\mathrm{D}$ & $>20$ & 246 & II & 0.165 & SC II \\
\hline 051SMX & Xianfeng, Shimian & 0.24 & SC II & $\mathrm{C}+\mathrm{D}$ & $>20$ & 283 & II & 0.25 & SC II \\
\hline
\end{tabular}


Continued from Table A

\begin{tabular}{|c|c|c|c|c|c|c|c|c|c|}
\hline \multirow{2}{*}{ Station code } & \multirow{2}{*}{ Station name } & \multicolumn{2}{|c|}{ HVSR classification } & \multirow{2}{*}{$\begin{array}{c}\text { Site class } \\
\text { of RSS } \\
\text { classification }\end{array}$} & \multicolumn{3}{|c|}{ Index classification } & \multirow{2}{*}{$\begin{array}{l}T_{\mathrm{m}} \\
/ \mathrm{s}\end{array}$} & \multirow{2}{*}{$\mathrm{RSC}$} \\
\hline & & $\begin{array}{l}T_{\mathrm{R}} \\
/ \mathrm{s} \\
\end{array}$ & Site class & & $\begin{array}{l}H \\
/ \mathrm{m} \\
\end{array}$ & $\begin{array}{c}v_{20} \\
/\left(\mathrm{m} \cdot \mathrm{s}^{-1}\right)\end{array}$ & $\begin{array}{c}\text { Site } \\
\text { class }\end{array}$ & & \\
\hline 051SPA & Anhong, Songpan & 0.16 & SC I & $\mathrm{B}$ & 15.5 & 282 & II & 0.168 & SC I \\
\hline 051SPC & Chuanzhusi, Songpan & 0.20 & SC I & $\mathrm{C}+\mathrm{D}$ & 13.9 & 314 & II & 0.177 & SC I \\
\hline 051SPT & Songpan & 0.85 & SC IV & E & & & & 0.12 & SC I \\
\hline 051TQL & Lianglu, Tianquan & 0.12 & $\mathrm{SC} \mathrm{I}$ & $\mathrm{B}$ & 7.8 & 281 & II & 0.131 & SC I \\
\hline 051WCW & Wolong, Wenchuan & 0.43 & SC III & $\mathrm{B}$ & 15.9 & 295 & II & 0.12 & SC I \\
\hline 051XJB & Earthquake Office of Xiaojin & 0.10 & SC I & B & $>20$ & 293 & II & 0.116 & SC I \\
\hline 051XJD & Dawei, Xiaojin & 0.33 & SC II & $\mathrm{C}+\mathrm{D}$ & $>20$ & 297 & II & & SC II \\
\hline 051XJL & Lihua, Xinjin & 0.31 & SC II & $\mathrm{C}+\mathrm{D}$ & & & & & SC II \\
\hline 051YAD & Earthquake Station of Ya'an & 0.35 & SC II & $\mathrm{C}+\mathrm{D}$ & 18.5 & 190 & II & 0.33 & SC II \\
\hline 051YAL & Shilong, Yingjing & 0.13 & SC I & B & & & & 0.118 & SC I \\
\hline 051YAM & Mingshan, Ya'an & 0.12 & SC I & $\mathrm{B}$ & & & & 0.11 & SC I \\
\hline 051YAS & Shaping, Ya'an & 0.08 & SC I & $\mathrm{B}$ & 6.5 & 226 & II & & SC I \\
\hline 051YXX & Xinmin, Yuexi & 0.40 & SC III & $\mathrm{C}+\mathrm{D}$ & $>20$ & 287 & II & & SC III \\
\hline 051YXZ & Zhongsuo, Yuexi & 0.13 & SC I & E & 19 & 323 & II & & SC I \\
\hline 062SHW & Shawan & 0.16 & SC I & $\mathrm{B}$ & & & & & SC I \\
\hline $062 \mathrm{TCH}$ & Dangchang & 0.18 & SC I & $\mathrm{C}+\mathrm{D}$ & & & & & SC I \\
\hline 062WIX & Wenxian & 0.25 & SC II & B & & & & & SC II \\
\hline 062WUD & Wudu & 0.90 & SC IV & $\mathrm{E}$ & & & & & SC IV \\
\hline 062ZHQ & Zhouqu & 0.18 & SC I & $\mathrm{C}+\mathrm{D}$ & & & & & SC I \\
\hline
\end{tabular}

Note: $T_{\mathrm{R}}$, the peak period of HVSR; $H$, the site overburden thickness; $v_{20}$, the equivalent shear-wave velocity of the top $20 \mathrm{~m} ; T_{\mathrm{m}}$, the site predominant period of microtremor analysis; RSC, the recommended site class. 